DOI: $10.12731 / 2070-7568-2020-1-40-54$

УДК 331.103: 35.088.7

\title{
ТРАНСФОРМАЦИЯ СИСТЕМЫ \\ УПРАВЛЕНИЯ ПЕРСОНАЛОМ В УСЛОВИЯХ \\ ВНЕДРЕНИЯ ПРОФЕССИОНАЛЬНЫХ СТАНДАРТОВ: ДОКУМЕНТАЦИОННОЕ ОБЕСПЕЧЕНИЕ
}

\section{Данилова А.С., Кутузова А.В.}

В данной статье анализируется вопрос модернизации системь управления персоналом в условиях внедрения профессиональных стандартов в разрезе вопроса документационного обеспечения, которое является фундаментом эффективного принятия решения в разрезе всех видов деятельности предприятия, в том числе и подсистеме «Персонал»; рассматриваются вопросы взаимодействия системы управления персоналом и системы профессиональных стандартов, через призму двух подходов основанных, на стандарте специалиста по управлению персоналом, путем выделение конкретной обобщающеей функиии, так и на общей действующей системе профстандартов, готовых к внедрению в деятельность организаций.

Цель работы: определение и описание подходов к трансформачии документационного обеспечения в условиях внедрения профессиональных стандартов, влияющих на эффективное функицонирование системы управления персоналом.

Метод или методология проведения работы: методическую основу составили системный, обобщённый, аналитический и сравнительный подходыл.

Результаты: в статье раскрыты основныле подходы, трансформации документационного обеспечения, влияющих н эффективное функционирование системы управления персоналом в условиях внедрения профессиональных стандартов и предложен ряд рекомендаций, обеспечивающих планирования организационного развития с учетом внедрения необходимых изменений. 
Область применения результатов: полученные результаты целесообразно учитывать при внедрении профессиональных стандартов в деятельность организаций любого типа, а также при формировании направлений кадровой стратегии.

Ключевые слова: персонал; профессиональные стандарты; система управления персоналом; документационное обеспечение; специиалист по управлению персоналом.

\section{TRANSFORMATION OF HUMAN \\ RESOURCES MANAGEMENT SYSTEM IN CONDITIONS OF IMPLEMENTATION OF PROFESSIONAL STANDARDS: DOCUMENTATION}

\section{Danilov A.S., Kutuzova A.V.}

This article analyses the process of personnel management system adjustment in the context of implementation of professional standards, primarily the issue of documentation; which is the main effective decision-making in the activities of all enterprises; the article also considers issues of interaction between the personnel management system and the professional standards system, highlights two approaches: the first is based on the function of a personnel management specialist, the second on the common operating system of professional standards ready to be implemented in the activities of organizations.

The purpose of the work is to define and describe approaches to the transformation of documentation support in the context of the introduction of professional standards affecting the effective functioning of the personnel management system.

The method or methodology of carrying out the work: the methodological basis was the system, generalized, analytical and comparative approaches.

Results: the article describes the main approaches and offers recommendations for the implementation of professional standards.

Scope of results: the received results need to be considered at introduction of professional standards in activity of all organizations and also when forming personnel strategy. 
Keywords: personnel; professional standards; personnel management system; documentary providing; Human Resources Specialist.

Организация деятельности персонала строится на подсистеме документационного обеспечения, поскольку именно документированная информация составляет основу эффективного принятия управленческих решений, как в области персонала, так и предприятия в целом.

Следует отметить, что вопрос трансформации подсистемы документационного обеспечения в рамках внедрения профессиональных стандартов как самостоятельная проблема до настоящего времени не ставилась и не рассматривалась. Однако отечественные теоретики и практики отдельно рассматривали такие смежных вопросов как: «управление документацией» и «организация документационного обеспечения» (Быкова Т.В., Васильев М.А, Кибанов А.Я., Ларин М.В., Рубцова И.О., Самусь И.В., Судник Т.В., Шенепович Г.Г. и др.); «проблемы и подходы внедрения профессиональных стандартов» (Митрофанова О.И., Непрокина И.В., Пчелинцева Т.С., Пуртова Н.В., Талапова Н.В., Федотова В.В., Шинявская С.И. и др.). Значительный объем исследования, выполненный по смежным направлениям, поставленной проблемы, и побудило к выбору темы исследования, которая бы обобщила основные подходы трансформации в сложившихся условиях.

Система управления наибольшей доли отечественных предприятий претерпевает ряд изменений, вызванных как международными событиями, так и национальными, в последнюю группу можно также отнести и вопросы внедрения профессиональных стандартов.

Точная трактовка дефиниции «профессиональный стандарт» (ПС), как «характеристики квалификации, необходимой работнику для осуществления определенного вида профессиональной деятельности, в том числе выполнения определенной трудовой функции» была определена в 2012 году в Трудовой кодекс Российской Федерации (ст. 195.1) на основе утвержденных Центром изучения проблем профессионального образования и Федеральным институтом развития документов 2007 года. 
Взаимодействие системы профессиональных стандартов и системы управления персоналом, возможно, рассмотреть не менее чем с двух подходов. Первый подход, ориентирован на выделении обобщенной трудовой функции «документационное обеспечение работы с персоналом» специалиста службы управления персоналом.

В рамках данного подхода хотелось бы отметить, что с 2016 года в силу вступил профессиональный стандарт «Специалист по управлению персоналом» (Приказ Министерства труда России от 06.10.2015 N 691н), в характеристиках обобщенных функций в рамках его содержания выделена функцию «документационное обеспечение работы с персоналом» (код А), структура данной функции представлена на рисунке 1.

Сложность данной обобщенной трудовой функции не велика, поскольку профессиональным стандартам присвоен пятый квалификационный уровень и минимальные требования к образованию наличие среднего профессиональное образование (рекомендована программа подготовки специалистов среднего звена) и/или дополнительное профессиональное образование (программы профессиональной переподготовки, программы повышения квалификации).

Также этот же профессиональный стандарт, рекомендует наименование должностей для реализующих эту функцию:

- для организаций, имеющих развитую организационную структуру (как правило, это средние и крупные предприятия): специалист по кадровому делопроизводству, специалист по документационному обеспечению работы с персоналом, специалист по документационному обеспечению персонала,

- для прочих организаций (микропредприятия и малые) - специалист по персоналу.

Организация реализации обобщенной трудовой функции «документационное обеспечение работы с персоналом» позволит обеспечить своевременное применения и разработку организационно-правовые инструментов успешного ведения и решения ряда кадровых вопросов по планированию потребности в персонале, найме и подборе, обучению, мотивации и высвобождению персонала. 


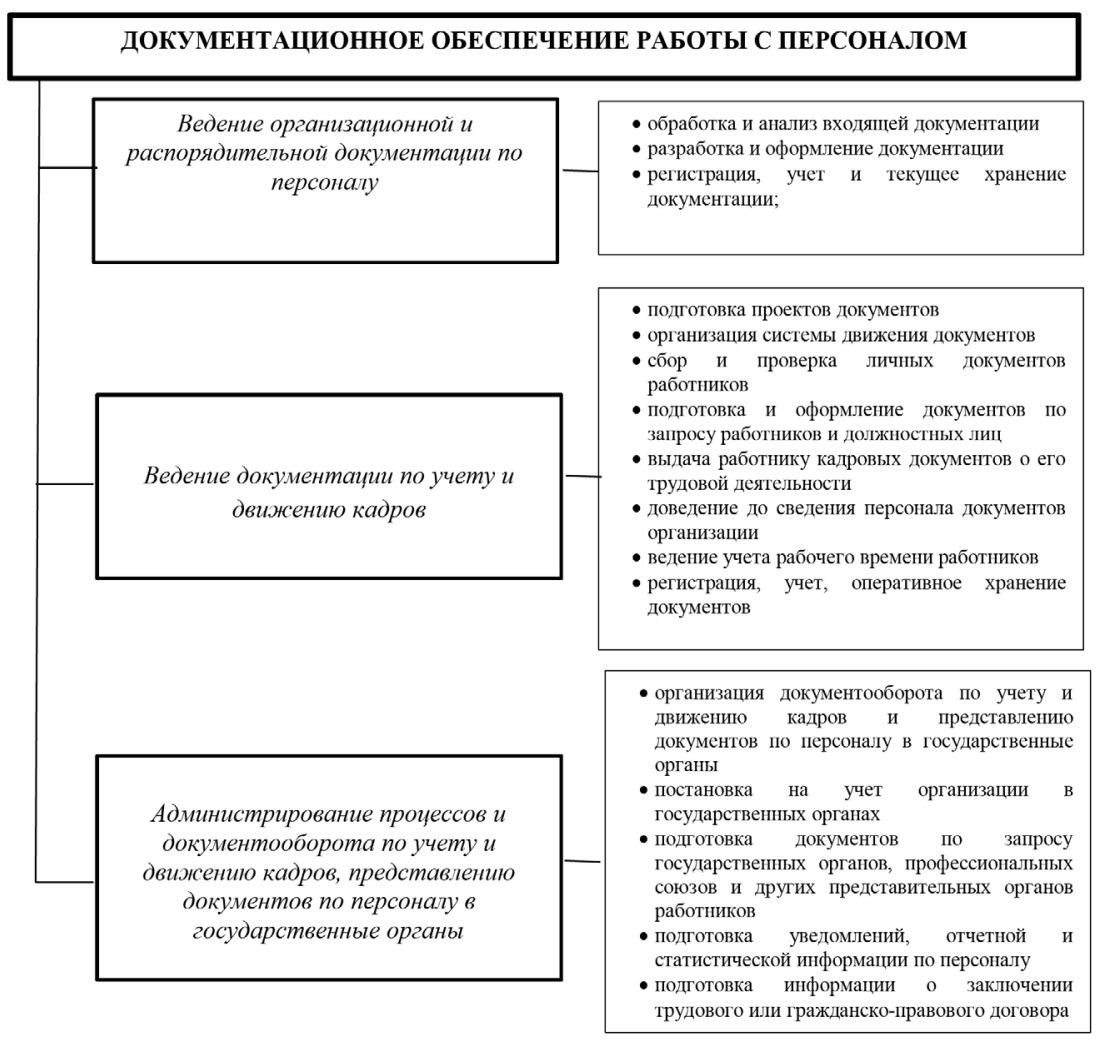

Рис. 1. Структура обобщенной функции «документационное обеспечение работы с персоналом» специалиста по управлению персоналом

Второй подход в проблеме, ориентирован на внесение изменений в организацию системы управления персоналов, в части документационного обеспечения. Цель разработки и внедрения профессиональных стандартов является упорядочивание процессов в сфере управления персоналом и повышения их эффективности (например, таких этапов, как отбор, найм, мотивация, аттестация, развитие); систематизации формирования отраслевой нормативной документации, реализации и сопровождения бизнес-процессов организации. Постановление Правительства РФ «Об особенностях применения профессиональных стандартов...» от 27.06.2016 № 584 пред- 
писывает, что с 2020 году внутренняя документация большинства организаций, должна быть приведена в соответствие принятым профессиональным стандартам (рисунок 2). Описанные локальные акты являются неотьемлемыми элементами процесса управления персоналом организации, в таблице 2 отображена взаимосвязь данных элементов и профессиональных стандартов.

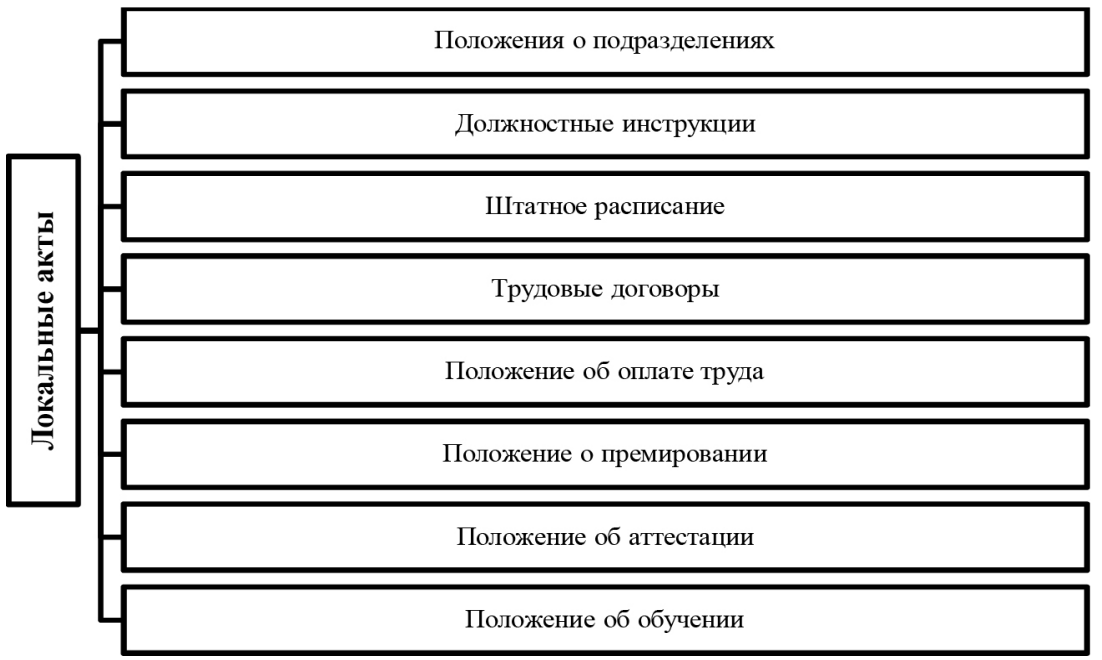

Рис. 2. Локальные акты учреждения, в которые вносятся изменения при внедрении профессиональных стандартов

Таблииа 2.

Взаимосвязь этапов процессов управления персоналом предприятия, локальных актов и профессиональных стандартов

\begin{tabular}{|c|c|c|c|c|c|c|c|c|c|}
\hline $\begin{array}{c}\text { Этап } \\
\text { процесса } \\
\text { управления } \\
\text { персоналом }\end{array}$ & $\begin{array}{c}\text { Цель этапа } \\
\text { перехода на профессиональные } \\
\text { стандарты }\end{array}$ & 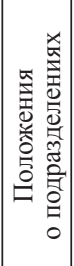 & 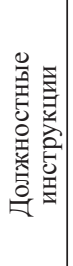 & 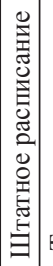 & 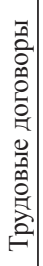 & 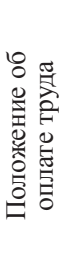 & 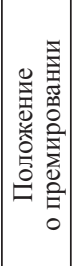 & 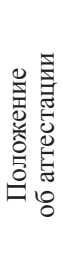 & 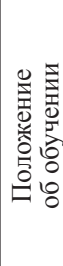 \\
\hline $\begin{array}{l}\text { Отбор } \\
\text { персонала }\end{array}$ & $\begin{array}{l}\text { Определение требований } \\
\text { к квалификации (знаниям, } \\
\text { умениям, навыкам, опыту ра- } \\
\text { боты) кандидатов в соответ- } \\
\text { ствии с ПС }\end{array}$ & & & & & & & & \\
\hline
\end{tabular}


Окончание табл. 2.

\begin{tabular}{|l|l|l|l|l|l|l|l|l|}
\hline $\begin{array}{l}\text { Найм } \\
\text { персонала }\end{array}$ & $\begin{array}{l}\text { Наименование профессии и } \\
\text { должностей, а также трудовых } \\
\text { функций работников с ПС }\end{array}$ & & & & & & & \\
\hline $\begin{array}{l}\text { Мотивация } \\
\text { персонала } \\
\text { (оплата труда) }\end{array}$ & $\begin{array}{l}\text { Система оплаты труда в со- } \\
\text { ответствии с квалификацион- } \\
\text { ными уровнями ПС }\end{array}$ & & & & & & & \\
\hline $\begin{array}{l}\text { Аттестация } \\
\text { персонала }\end{array}$ & $\begin{array}{l}\text { Организация процесса атте- } \\
\text { стации в соответствии с квали- } \\
\text { фикационными требованиями } \\
\text { должности, указанными в ПС }\end{array}$ & & & & & & & \\
\hline $\begin{array}{l}\text { Развитие персо-- } \\
\text { нала (обучение) }\end{array}$ & $\begin{array}{l}\text { Организация системы обуче- } \\
\text { ния в соответствии с ПС }\end{array}$ & & & & & & & \\
\hline
\end{tabular}

Большинство организаций столкнулись с проблемой перехода на профессиональные стандарты в связи с несовершенством действующей системы управления.

На наш взгляд, рациональным способом управления таким нововведениям как «профстандарт», является следования процессному подходу, исходя из данной логики переход на профессиональные стандарты, есть не что иное как проект.

В рамках данного проекта необходимо предусмотреть ряд мероприятий, таких как создание проектной группы, разработка и утверждение план-графика работы по внедрению профстандартов, ознакомление коллектива учреждения с требованиями законодательства в части внедрения профстандартов и результатами работы ответственной группы.

Данные рекомендации целесообразно систематизировать и представить в виде комплексной программы (рисунок 3), поскольку она является инструментом проектного подхода, который эффективно помогает решать задачи планирования организационного развития в различных направлениях деятельности организаций различного типа.

В процессе реализации проекта осуществляются три основных мероприятия:

1. Организация рабочей (проектной) группы (при формировании временной проектной группы издается приказ, который утверждает состав группы, как правило это представители из ключевых подразделений, и ее руководителя, а также может закрепить их полномочия. 


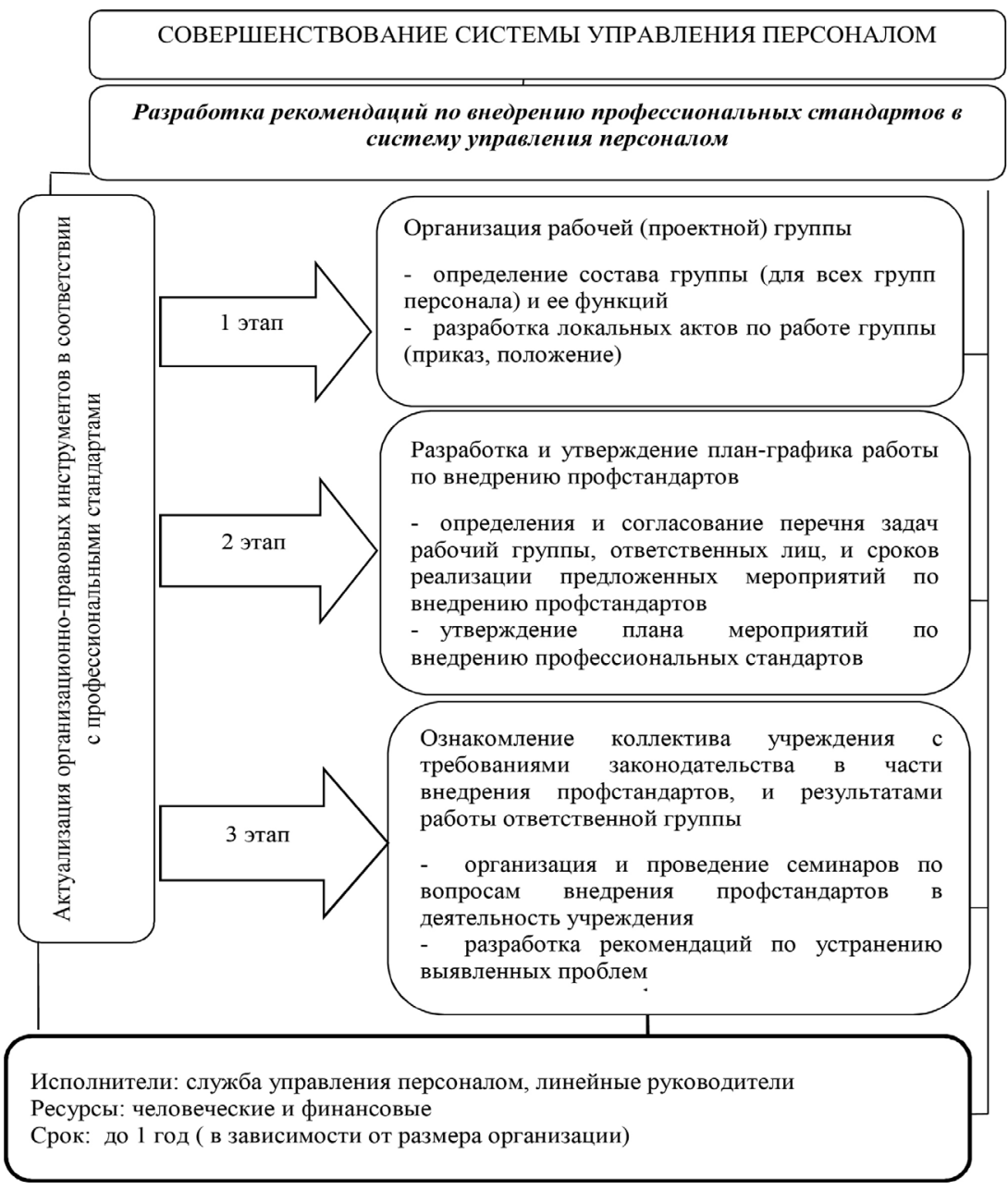

Рис. 3. Комплексная программа рекомендаций по внедрению профессиональных стандартов

Полномочия рабочей группы представлены ограниченным правом использования ресурсов учреждения и делегированием части задач, необходимых для внедрения профстандартов, для разработки другим специалистам. В том числе к основным правам специалистов рабочей группы относится: 
- получение доступа к любым локальным документам и техническим ресурсам учреждения, необходимым для решения поставленных задач;

- приобретение полномочий по изданию необходимых распоряжений в адрес работников учреждения при внедрении профстандартов;

- содействие руководству учреждения в решении организационных вопросов, в обеспечении взаимодействия с различными сторонними субъектами в процессе внедрения профстандартов.

К обязанностями специалистов группы можно отнести добросовестное выполнение функций, предусмотренных положением, следование порядку и план-графику внедрения профстандартов; составление отчетов по реализации мероприятий, намеченных планом. Основные функции рабочей группы представлены в таблице 18.

Таблицуа 2.

Основные функции рабочей группы по внедрению профстандартов в деятельность предприятия

\begin{tabular}{|c|c|c|c|}
\hline $\begin{array}{l}\text { Наименова- } \\
\text { ние функции }\end{array}$ & Содержание функции & $\begin{array}{c}\text { Ответствен- } \\
\text { ные лица }\end{array}$ & $\begin{array}{c}\text { Локальный } \\
\text { акт }\end{array}$ \\
\hline $\begin{array}{l}\text { Информаци- } \\
\text { онная }\end{array}$ & $\begin{array}{l}\text { Формирование рабочей группой инфор- } \\
\text { мационных, справочных баз, методи- } \\
\text { ческих рекомендаций, регламентов для } \\
\text { сотрудников организации, так или иначе } \\
\text { вовлеченных в процесс внедрения проф- } \\
\text { стандартов }\end{array}$ & $\begin{array}{l}\text { Руководитель } \\
\text { службы УП }\end{array}$ & $\begin{array}{l}\text { Методические } \\
\text { рекомендации } \\
\text { по составле- } \\
\text { нию долж- } \\
\text { ностных ин- } \\
\text { струкций } \\
\end{array}$ \\
\hline $\begin{array}{l}\text { Консультатив- } \\
\text { но-координа- } \\
\text { ционная }\end{array}$ & $\begin{array}{l}\text { Оказание специалистами рабочей груп- } \\
\text { пы необходимой помощи другим со- } \\
\text { трудникам, участвующим во внедрении } \\
\text { профстандартов, в обеспечении обрат- } \\
\text { ной связи между данными сотрудниками } \\
\text { и руководством, между руководством и } \\
\text { вышестоящими организациями, а также } \\
\text { иными уполномоченными и заинтересо- } \\
\text { ванными субъектами. }\end{array}$ & $\begin{array}{l}\text { Линейные ру- } \\
\text { ководители }\end{array}$ & $\begin{array}{l}\text { Служебные за- } \\
\text { писки }\end{array}$ \\
\hline $\begin{array}{l}\text { Аналитиче- } \\
\text { ская }\end{array}$ & $\begin{array}{l}\text { Мониторинг внедрения ПС в организа- } \\
\text { ции, проведении анализа его результа- } \\
\text { тов, осуществлении их интерпретации, } \\
\text { инициировании необходимых корректи- } \\
\text { ровок в процесс внедрения ПС. }\end{array}$ & $\begin{array}{l}\text { Линейные ру- } \\
\text { ководители }\end{array}$ & $\begin{array}{l}\text { Отчеты под- } \\
\text { разделений }\end{array}$ \\
\hline
\end{tabular}


Организация проектной группы предполагает изменение организационной структуры, на время внедрения предложенных рекомендаций на более сложную структуру (матричную). Руководитель проектной (рабочей) группы, наделен необходимыми полномочиями для внедрения рекомендаций по совершенствованию системы управления персоналом в соответствии с профессиональными стандартами.

2. В соответствии с приказом проектная группа разрабатывает пошаговый план работ по внедрению профстандартов. В плане указываются задачи и сроки их выполнения, ответственные исполнители и ожидаемые результаты.

3. На конечном этапе организуются и проводятся семинары (1 раз в квартал) и собрание трудового коллектива (1 раз в месяц) по вопросам внедрения профстандартов в деятельность предприятия, а также разрабатываются мероприятия по устранению выявленных проблем. На этом же этапе издается приказ о внесении изменений и происходит ознакомление сотрудников с ним.

Обобщая выше сказанное, хотелось бы еще раз отметить, что подсистема документационного обеспечения это важная составляющая всей системы управления персоналом, и ее трансформация сегодня обусловлена внедрением профессиональных стандартов, которые внесли ряд корректив, тем самым определив четкие рамки функционирования подсистемы.

Процедура трансформации как было определено ранее, строится на двух ключевых подходах: первый - ориентирован на функции специалиста службы управления персоналом, вплоть до концентрации данной функции в руках конкретного сотрудника (обобщенная трудовая функция А профессионального стандарта «Специалист по управлению персоналом»), второй - на процедуры внесение изменений в организацию системы управления персоналов, в части документационного обеспечения (общие рекомендации по внедрению профессиональных стандартов). И тот и другой подходы требует пристальной организации и контроля, поскольку затрагивают существенные условия труда конкретного сотрудника (первый подход) или персонала в целом (второй подход). Данные аспекты необходимо учитывать при 
формировании стратегии предприятия, в том числе ее кадровой составляющей, следование предложенным же рекомендациям позволят оптимизировать данную работу и избежать ряда кадровых рисков.

\section{Список литературы}

1. Данилова А.С. Актуальные аспекты внедрения профессиональных стандартов: должностные инструкции// Инновационные технологии на железнодорожном транспорте Труды XXII Межвузовской научно-практической конференции КрИЖТ ИрГУПС. Красноярск, 2018. С. 146-151.

2. Данн А.В., Шендель Т.В. Организация труда специалистов в области управления персоналом // Международный научно исследовательский журнал. 2013. № 10-3. С. 94-96.

3. Долженкова Ю.В., Бабынина Л.С. Внедрение профессиональных стандартов: новые возможности и вызовы // Самоуправление. 2019. T. 2. № 1. С. 205-207.

4. Ерофеева А.П. Модернизация системы управления персоналом на предприятиях сферы услуг: диссертация ... кандидата экономических наук: 08.00.05. Великий Новгород, 2014. 141 с.

5. Залуцкий М.А., Данилова А.С. Роль профессиональных стандартов в социально-трудовых отношениях // Вестник Сургутского государственного университета. 2016. № 4 (14). С. 10-13.

6. Малахова А.А. Оценка персонала организации на основе компетентностного подхода // Социально-экономический и гуманитарный журнал Красноярского ГАУ. 2016. № 4. С. 90-103.

7. Митрофанова О. И. Профессиональные стандарты: Учебно-практическое пособие / Митрофанова О.И., Кузнецов Д.Л. Москва: Контракт, НИЦ ИНФРА-M, 2017. 136 с. URL: https://znanium.com/ catalog/product/954301

8. Непрокина И.В., Пчелинцева Т.С. Практическое пособие «Как работать с профессиональными стандартами». URL: http://dom-hors.ru/rus/files/ arhiv_zhurnala/spp/2016/4/pedagogics/neprokina-pchelintseva.pdf

9. Приказ Министерства труда России от 06.10.2015 N 691н «Об утверждении профессионального стандарта «Специалист по управ- 
лению персоналом» (Зарегистрировано в Минюсте РФ 19.10.2015 N 39362).

10.Сурат И.Л., Борщева А.В., Ильченко С.В. Документационное обеспечение управления человеческими ресурсами: учебное пособие. М., 2019. 150 c.

11. Телешева О.Г., Якимова Л.Д. Использование функционального подхода при анализе организации работы службы управления персоналом // Проблемы социально-экономического развития в новых экономических условиях: взгляд молодых исследователей : сборник статей участников Международной научно-практической конференции IV Уральского вернисажа науки и бизнеса. Сер. «Экономика: профессионализм и творчество» / Под общей редакцией Е.П. Велихова. Екатеринбург, 2017. С. 266-271.

12. Тесля А.Е., Кутузова А.В. Формирование кадровой политики//Молодые ученые в решении актуальных проблем науки: сборник материалов Всероссийской научно-практической конференции студентов, аспирантов и молодых ученых / Под общей редакцией Ю.Ю. Логинова. Красноярск. 2017. С. 632-634.

13. Хлуткова О.С., Кутузова А.В. Анализ и совершенствование кадровой политики организации // Повышение управленческого, экономического, социального и инновационно-технического потенциала предприятий, отраслей и народнохозяйственных комплексов сборник статей X Международной научно-практической конференции. Пенза. 2019. С. 265-268.

14.Щедрина И.В., Клименкова Т.А. К вопросу обновления стратегии управления человеческими ресурсами // Экономика и предпринимательство. 2015. № 8-1 (61-1). С. 1145-1147.

15. Яркова С.А., Якимова Л.Д., Данилова А.С. Компетентностный подход в подготовке HR-менеджеров: от образовательного к профессиональному стандарту // Экономика труда. 2018. Том 5. № 1. С. 43-60.

\section{References}

1. Danilova A.S. Innovatsionnye tekhnologii na zheleznodorozhnom transporte Trudy XXII Mezhvuzovskoy nauchno-prakticheskoy konferentsii 
KrIZhT IrGUPS [Innovative technologies in railway transport Proceedings of the XXII Interuniversity Scientific and Practical Conference KrIZhT IrGUPS]. Krasnoyarsk, 2018, pp. 146-151.

2. Dunn A.V., Shendel T.V. Mezhdunarodnyy nauchno issledovatel'skiy zhurnal. 2013. No. 10-3, pp. 94-96.

3. Dolzhenkova Yu.V., Babynina L.S. Samoupravlenie. 2019.Vol. 2. No. 1, pp. 205-207.

4. Erofeeva A. P. Modernizatsiya sistemy upravleniya personalom na predpriyatiyakh sfery uslug [Modernization of the personnel management system at service enterprises]: the dissertation ... of the candidate of economic sciences: 08.00.05. Veliky Novgorod, 2014. 141 p.

5. Zalutsky M.A., Danilova A.S. Vestnik Surgutskogo gosudarstvennogo universiteta. 2016. N 4 (14), pp. 10-13.

6. Malakhova A.A. Sotsial'no-ekonomicheskiy i gumanitarnyy zhurnal Krasnoyarskogo GAU. 2016. N 4, pp. 90-103.

7. Mitrofanova O.I., Kuznetsov D.L. Professional'nye standarty [Professional standards]: Training and practical manual. Moscow: Contract, SIC INFRA-M, 2017. 136 p. https://znanium.com/catalog/product/954301

8. Neprokina I.V., Pchelintseva T.S. Prakticheskoe posobie «Kak rabotat' s professional'nymi standartami» [Practical guide "How to work with professional standards"]. http://dom-hors.ru/eng/files/arhiv_zhurnala/ spp/2016/4/pedagogics/neprokina-pchelintseva.pdf

9. Prikaz Ministerstva truda Rossii ot 06.10.2015 N 691n «Ob utverzhdenii professional'nogo standarta «Spetsialist po upravleniyu personalom» (Zaregistrirovano $v$ Minyuste $R F$ 19.10.2015 N 39362) [Order of the Ministry of Labor of Russia dated 06.10.2015 N 691 " On the approval of the professional standard" Personnel Management Specialist "(Registered in the Ministry of Justice of the Russian Federation on 10.19.2015 N 39362)].

10. Surat I.L., Borshcheva A.V., Ilchenko S.V. Dokumentatsionnoe obespechenie upravleniya chelovecheskimi resursami [Human Resource Management Documentation]: A Training Manual. M., 2019. 150 p.

11. Telesheva O.G., Yakimova L.D. Problemy sotsial'no-ekonomicheskogo razvitiya v novykh ekonomicheskikh usloviyakh: vzglyad molodykh issledovateley : sbornik statey uchastnikov Mezhdunarodnoy nauchno-prak- 
ticheskoy konferentsii IV Ural'skogo vernisazha nauki i biznesa. Ser. "Ekonomika: professionalizm i tvorchestvo" [Problems of socio-economic development in the new economic conditions: a view of young researchers: a collection of articles by participants of the International Scientific and Practical Conference of the IV Ural Vernissage of Science and Business. Ser. "Economics: professionalism and creativity"] / ed. E.P. Velikhov. Yekaterinburg, 2017. S. 266-271.

12. Teslya A.E., Kutuzova A.V. Molodye uchenye v reshenii aktual'nykh problem nauki: sbornik materialov Vserossiyskoy nauchno-prakticheskoy konferentsii studentov, aspirantov i molodykh uchenykh [Young scientists in solving urgent problems of science: a collection of materials of the All-Russian scientific and practical conference of students, graduate students and young scientists] / Ed. Yu.Yu. Loginov. Krasnoyarsk 2017, pp. 632-634.

13. Khlutkova O.S., Kutuzova A.V. Povyshenie upravlencheskogo, ekonomicheskogo, sotsial'nogo i innovatsionno-tekhnicheskogo potentsiala predpriyatiy, otrasley i narodnokhozyaystvennykh kompleksov sbornik statey $X$ Mezhdunarodnoy nauchno-prakticheskoy konferentsii [Improving the managerial, economic, social and innovative-technical potential of enterprises, sectors and national economic complexes collection of articles of the X International Scientific and Practical Conference]. Penza, 2019, pp. 265-268.

14. Shchedrina I.V., Klimenkova T.A. Ekonomika i predprinimatel'stvo. 2015. N 8-1 (61-1), pp. 1145-1147.

15. Yarkova S.A., Yakimova L.D., Danilova A.S. Ekonomika truda [Labor Economics]. 2018. Volume 5. N 1, pp. 43-60.

\section{ДАННЫЕ ОБ АВТОРАХ}

Данилова Альбина Сергеевна, доцент кафедры «Управление персоналом», кандидат экономических наук, доцент Красноярский институт железнодорожного транспорта филиал Федерального государственного бюджетного образовательного учреждения высшего образования «Иркутский государственный университет путей сообщения» ул. Новая Заря, 2И, г. Красноярск, 660028, Российская Федераџия danilovi2008@yandex.ru 
Кутузова Анастасия Валерьевна, доцент кафедры «Управление персоналом», кандидат педагогических наук Красноярский институт железнодорожного транспорта филиал Федерального государственного бюджетного образовательного учреждения высшего образования «Иркутский государственный университет путей сообщения» ул. Новая Заря, 2И, г. Красноярск, 660028, Российская Федераџия kutuzova_av@krsk.irgups.ru

\section{DATA ABOUT THE AUTHORS}

Danilova Al'bina Sergeevna, Associate Professor of the Department «Human resources management», Candidate of Economic Sciences, Associate Professor

Irkutsk State Transport University, Krasnoyarsk Institute of Railway Transport

2I, Novaya Zarya Str., Krasnoyarsk, 660028, Russian Federation danilovi2008@yandex.ru

SPIN-code: 9811-8265

ORCID: 0000-0001-9094-8353

Kutuzova Anastasiya Valer'evna, Associate Professor of the Department «Human resources management», Candidate of Pedagogical Sciences

Irkutsk State Transport University, Krasnoyarsk Institute of Railway Transport

2I, Novaya Zarya Str., Krasnoyarsk, 660028, Russian Federation kutuzova_av@krsk.irgups.ru

ORCID: 0000-0002-6984-8515 